\title{
Possible Association between Serotonin Transporter Gene Polymorphism and Suicide Behavior in Major Depressive Disorder
}

\author{
Hwa-Young Lee ${ }^{1 *}$, Jin-Pyo Hong ${ }^{2 *}$, Jung-A Hwang ${ }^{4}$, Heon-Jeong Lee, \\ Ho-Kyung Yoon ${ }^{4}$, Bun-Hee Lee $^{3}$, and Yong-Ku Kim ${ }^{4} \bowtie$ \\ ${ }^{1}$ Department of Psychiatry, Soonchunhyang University College of Medicine, Seoul, Republic of Korea \\ ${ }^{2}$ Department of Psychiatry, University of Ulsan College of Medicine, Asan Medical Center, Seoul, Republic of Korea \\ ${ }^{3}$ Department of Psychiatry, Gangnam Eulji Hospital, Eulji University, Seoul, Republic of Korea \\ ${ }^{4}$ Department of Psychiatry, Korea University College of Medicine, Seoul, Republic of Korea
}

Objective The serotonin transporter (5-HTT) genes are major candidate genes for modulating the suicidal behavior. We investigated the association between serotonin transporter polymorphisms and suicidal behavior in patients with major depressive disorder (MDD).

Methods Serotonin transporter intron 2 VNTR polymorphism (5-HTTVNTR) and serotonin transporter linked polymorphic region polymorphism (5-HTTLPR) were analyzed in 132 depressed patients with suicidal attempt as well as in 122 normal controls. Hamilton's 17-item Depression Rating Scale (HDRS), the Risk-Rescue rating system (RRR) and the Lethality Suicide Attempt Rating Scale updated (LSARS-II) were assessed for the depressed patients.

Results Although not statistically significant, a trend was found such that the 10/10 and 10/12 alleles of 5-HTTVNTR were more common in suicidal subjects than in control subjects. Comparing allele frequency, those with a 10 allele or 10 allele carriers were higher in suicidal subjects than in control subjects. No difference was noted in 5-HTTLPR genotypes and haplotype distribution between the suicidal subjects and control subjects. The RRR scores in subjects with the 10/10 5-HTTVNTR genotype or 10 5-HTTVNTR allele were significantly lower than those in subjects with other genotypes.

Conclusion These results show the possibility that 10 allele of 5-HTTVNTR is related to suicidal behavior in the suicidal subjects with MDD and suggest that 12 allele of 5-HTTVNTR might be related to more lethality in the suicidal subjects with MDD.

Psychiatry Investig 2015;12(1):136-141

Key Words Serotonin transporter, Polymorphism, Haplotype, Suicide, Major depressive disorder.

\section{INTRODUCTION}

Across the globe, approximately one million people kill themselves every year. ${ }^{1}$ Suicide represents a serious public health problem worldwide. According to the Organization for Economic Cooperation and Development (OECD), South Korea has one of the higher rates of suicide, among OECD countries. ${ }^{2}$ Approximately $60 \%$ of all suicides occur in the context of mood disorders. ${ }^{3}$ The serotonin transporter (5-HTT) is

Received: July 9, 2013 Revised: December 18, 2013

Accepted: March 26, 2014 Available online: January 12, 2015

$\triangle$ Correspondence: Yong-Ku Kim, MD, PhD

Department of Psychiatry, College of Medicine, Korea University, Ansan Hospital, 123 Jeokgeum-ro, Ansan 425-020, Republic of Korea

Tel: +82-31-412-5140, Fax: +82-31-412-5144, E-mail: yongku@korea.ac.kr

*These authors contributed equally to this work.

(a) This is an Open Access article distributed under the terms of the Creative Commons Attribution Non-Commercial License (http://creativecommons.org/licenses/by$\mathrm{nc} / 3.0$ ) which permits unrestricted non-commercial use, distribution, and reproduction in any medium, provided the original work is properly cited. the major determinant of serotonin inactivation following serotonin release at synapses, and it is the target for many antidepressants. Moreover, a decrease in central 5-HTT has also been observed in suicide victims with mood disorders. ${ }^{4} \mathrm{Ge}$ netic factors have been generally implicated in the etiology of suicide, although the precise mechanism and amount of genetic contribution have not yet been established. ${ }^{5}$ Therefore, the 5-HTT gene is considered to be a promising candidate to explain various psychiatric disorders, including suicidal behavior.

The serotonin transporter gene is located on chromosome 17q11.1-q12, and two polymorphisms have been reported: first, the various number of tandem repeats (VNTR) of 17 base pairs in intron 2 with three different numbers repeated $(9,10$, $12)^{6}$; second, the bi-allelic insertion/deletion polymorphism in the promoter region, with the deletion (or short=S) and the insertion (or=L) alleles localized upstream from the transcrip- 
tion start site. ${ }^{7}$

The VNTR polymorphism on intron 2 (5-HTTVNTR) was previously thought to be functionless, however, a recent study with transgenic mice demonstrated that 5-HTTVNTR acts as a transcriptional regulator within an area of the hindbrain, and that the 12-repeat allele was better able to induce transcription than was the 10-repeat analog. ${ }^{8}$ Many studies have demonstrated associations between the 5-HTTVNTR and major depressive disorder. ${ }^{9,10}$ There are also many studies investigating the association between 5 -HTTVNTR and suicide. $^{11-14}$

On the other hand, $\mathrm{S}$ allele in serotonin transporter linked polymorphic region polymorphism (5-HTTLPR) has been reported to be associated with reduced serotonin uptake in platelets compared with L allele. ${ }^{15,16}$ An association between this polymorphism and major psychiatric disorders has been reported, ${ }^{17,18}$ whereas other studies have reported no association. ${ }^{19,20}$

In this study, we investigated the associations between the serotonin transporter gene polymorphisms (5-HTTVNTR and 5-HTTLPR) and suicide behavior of major depressive disorder patients.

\section{METHODS}

\section{Subjects}

One hundred thirty-two subjects with major depressive disorder were recruited from among patients admitted to the emergency rooms of the Korea University Medical Center Ansan Hospital following suicide attempts. Initial psychiatric interviews were conducted by psychiatrist within 1 and again 24 hours after admission to the emergency room, and the subjects were diagnosed according to DSM-IV criteria. We defined suicide attempt as self-harming behaviors with at least some intent to end one's life. Subjects were excluded if their self-injurious behaviors were determined to have no suicidal intention or ideation.

Subjects suffering from alcohol or substance dependence or who had any comorbid diagnosis including bipolar disorder, schizophrenia or dementia based on DSM-IV criteria were excluded from the study. Patients with serious or unstable medical illness were also excluded from the study. There were twenty-eight patients who were smokers who were included in the present study. All subjects were at least 18 years of age.

The control subjects consisted of randomly selected healthy individuals who visited the Korea University Ansan hospital for regular health screenings. Subjects were excluded if they had any self-reported personal, familial psychiatric history or psychotropic medication history, or if they had scores of $\geq 10$ on the Beck Depression Inventory (BDI) or $\geq 40$ on the State-
Trait Anxiety Inventory (STAI). Finally, 122 control subjects were selected. The study protocol was approved by the Ethics Committee of Korea University, and written informed consent was obtained from all subjects. All patients and control subjects were at least 18 years of age and of Korean ethnicity.

\section{Clinical evaluation}

Individuals in the patient groups were evaluated independently by two trained psychiatrists. Diagnoses and ratings were decided by mutual consent of the psychiatrists. The evaluations consisted of reviews of psychiatric and medical histories, current and previous medication and alcohol intake, followed by a semi-structured interview for the purpose of establishing DSM-IV criteria diagnosis. We also administered Hamilton's 17-item Depression Rating Scale. ${ }^{21}$ We evaluated the lethality of individual suicide attempts using Weisman and Worden's Risk-Rescue rating (RRR) system ${ }^{22}$ and the Lethality Suicide Attempt Rating Scale-updated (LSARS-II). ${ }^{23,24}$

According to the RRR system, lethality is expressed as the ratio of five risk and five rescue factors that are operationally defined, weighted, and scored. ${ }^{25}$ The LSARS ${ }^{23}$ is an 11-point offering an appendix listing drugs, chemicals and lethal ranges of ingestion by body weight. The LSARS- $\mathrm{II}^{24}$ includes a table of drugs and chemicals, based on current medications and recent data on the minimum lethal doses in humans. ${ }^{25}$

\section{Blood sample collection and testing}

After written informed consent was obtained, venous blood was drawn from antecubital vein of each subject.

\section{Genotyping}

Genotyping of the 5-HTTVNTR was carried out using a previously described method. ${ }^{9}$ Genomic DNA was isolated from buffy coat by a genomic DNA purification kit (Promega, Madison, WI, US). Target DNA was amplified via polymerase chain reaction with oligonucleotide primers 8224(5'-GTCAGTATCACAGGCTGCGAG) and 8223(5'-TGTTCCTA GTCTTACGCCAGTG). This primer pair amplifies across the VNTR region of intron 2 that contains the $17 \mathrm{bp}$ repetitive element. PCR was performed in a final volume of $25 \mathrm{uL}$ containing $50 \mathrm{ng}$ of genomic DNA, $0.2 \mathrm{mM}$ dNTPs, $10 \mathrm{pmoL}$ of each primer, $10 \mathrm{mM}$ Tris- $\mathrm{HCl}(\mathrm{pH} 8.3), 50 \mathrm{mM} \mathrm{KCl}, 1.5 \mathrm{mM}$ $\mathrm{MgCl} 2,0.01 \%$ gelatin and 1 unit of Taq DNA polymerase. PCR amplification consisted of 35 cycles at $95^{\circ} \mathrm{C}(1 \mathrm{~min})$, $58^{\circ} \mathrm{C}(1 \mathrm{~min})$ and $72^{\circ} \mathrm{C}(1 \mathrm{~min})$. Amplified fragments were separated on $3 \%$ agarose gels, and bands were visualized via ethidium bromide staining and ultraviolet transillumination.

For the polymerase chain reaction (PCR) analysis in 5-HTTLPR, the forward primer 50-GGC GTT GCC GCT CTG AAT TGC-30 and the reverse primer 50-GAG GGA CTG 
AGC TGG ACA ACC CAC-30 were employed. A 25 mL PCR analysis was performed according to a protocol previously described. ${ }^{16}$ PCR products were separated on $3 \%$ agarose gels supplemented with ethidium bromide to allow identification of the long (528 bp) and the short (484 bp) variants.

\section{Statistical analysis}

Pearson chi-square tests were performed in order to test the categorical variables (e.g., gender and diagnosis) to test for deviations from Hardy-Weinberg equilibrium. Group mean differences were ascertained using a Student's t-test or analysis of variance (ANOVA) according to the number in each group. Haplotype analysis of serotonin transporter gene polymorphism was performed. A probability value of $\mathrm{p}<0.05$ was considered statistically significant. Probability values were corrected by multiplying the number of comparisons made (Bonferroni correction). All statistical analyses were performed with SPSS version 12.01 for Windows.

\section{RESULTS}

The gender distribution did not differ significantly between control subjects (63 males/59 females) and suicidal subjects (53 males/79 females; $\mathrm{p}=0.07$ ). There was no significant difference in the age distribution between suicidal subjects and control subjects $(34.9 \pm 13.3$ years, mean $\pm S D$ in suicidal subjects and 34.1 \pm 12.7 years in control subjects, $p=0.64)$. Methods of suicide attempt included drug ingestion $(n=53,40.1 \%)$, wrist cutting with superficial laceration $(n=15,11.3 \%)$, wrist cutting with deep laceration $(n=22,16.7 \%)$, pesticide or agricultural chemical ingestion $(n=27,20.5 \%)$, fall down $(n=6$, $4.5 \%)$, hanging $(n=3,2.3 \%)$, and miscellaneous other methods $(\mathrm{n}=6,4.5 \%)$.

Table 1 shows the distribution of 5-HTTVNTR genotypes for the two groups. We found few subjects with a 10/10 genotype in either group. The genotype distributions for the two groups were in Hardy-Weinberg equilibrium. Despite not reaching statistical significance $(\mathrm{p}=0.08)$, the incidence of 10 / 10 and 10/12 genotypes was higher in suicidal subjects than in the control subjects. Comparing allele frequency, 10 allele or 10 allele carriers were more frequently found in suicidal subjects than in control subjects. After Bonferroni correction, the statistical significance disappeared.

Table 2 shows the distribution of 5-HTTLPR genotypes for the two groups. We found few subjects with L/L genotype in either group. The genotype distributions for the two groups were in Hardy-Weinberg equilibrium. There was no significant difference in 5-HTTLPR genotype distribution between suicidal subjects and control subjects.

Haplotype frequencies calculated from the genotypic data for both groups are presented in Table 3. No difference was noted in haplotype distribution between the suicidal subjects and control subjects.

Across all participants, HDRS, LSARS-II, RRR scores were $20.3 \pm 8.5,4.0 \pm 2.1,34.3 \pm 15.0$ respectively. Table 4 shows the scores on three psychiatric scales according to 5-HTTVNTR genotype. There were no significant differences in the HDRS and LSARS-II according to the 5-HTTVNTR genotype. The RRR score in the subjects with 10/10 genotype of 5-HTTVNTR polymorphism was significantly lower than those in the subjects with other genotypes. The RRR score of the subjects with 10 allele was significantly lower than that of the subjects with 12 allele. After Bonferroni correction, the statistical significance sustained. The RRR score of 10 allele carriers were lower than that of 10 allele non-carriers (data not shown, $\mathrm{p}=$ 0.028). After Bonferroni correction, the statistical significance disappeared.

There were no significant differences in the HDRS, LSARS-

Table 1. Distributions of 5-HTTVNTR polymorphism and allele frequencies of the subjects

\begin{tabular}{|c|c|c|c|c|c|c|c|}
\hline & \multicolumn{3}{|c|}{ Genotype } & \multicolumn{2}{|c|}{ Allele } & \multicolumn{2}{|c|}{ Allele carrier } \\
\hline & $10 / 10$ & $10 / 12$ & $12 / 12$ & 10 & 12 & $10^{+}$ & $10^{-}$ \\
\hline Suicidal subjects with MDD (\%)* & $4(3.0)$ & $33(25.0)$ & $95(72.0)$ & $41(15.5)$ & $223(84.5)$ & $37(28.0)$ & $95(72.0)$ \\
\hline Control subjects $(\%)^{\dagger}$ & $3(2.5)$ & $17(13.9)$ & $102(83.6)$ & $23(9.4)$ & $221(90.6)$ & $20(16.4)$ & $102(83.6)$ \\
\hline
\end{tabular}

Genotypes: $\chi^{2}=5.12, \mathrm{df}=2, \mathrm{p}=0.08\left(\mathrm{p}_{\text {corr }}=0.16\right)$; alleles: $\chi^{2}=4.29, \mathrm{df}=1, \mathrm{p}=0.04\left(\mathrm{p}_{\text {corr }}=0.08\right)$; allele carriers: $\chi^{2}=4.93, \mathrm{df}=1, \mathrm{p}=0.026\left(\mathrm{p}_{\text {corr }}=0.052\right)$. $10^{+}: 10$ carrier, $10^{-}: 10$ non-carrier. ${ }^{*}$ Hardy-Weinberg equilibrium test for suicidal group: $\chi^{2}=2.969, \mathrm{df}=1, \mathrm{p}=0.08$, ${ }^{\dagger}$ Hardy-Weinberg equilibrium test for control group: $\chi^{2}=2.668, \mathrm{df}=1, \mathrm{p}=0.10$. $\mathrm{p}_{\text {corr: }}$ : $\mathrm{p}$-value after Bonferroni correction, MDD: major depressive disorder

Table 2. Distributions of 5-HTTLPR polymorphism and allele frequencies of the subjects

\begin{tabular}{lcccccc}
\hline & \multicolumn{3}{c}{ Genotype } & & \multicolumn{3}{c}{ Allele } \\
\cline { 2 - 3 } & L/L & L/S & S/S & & L & S \\
\hline Suicidal subjects with MDD (\%)* & $9(6.8)$ & $45(34.1)$ & $78(59.1)$ & & $63(23.9)$ & $201(76.1)$ \\
Control subjects (\%) & $6(4.9)$ & $46(37.7)$ & & & & \\
\hline
\end{tabular}

Genotypes: $\chi^{2}=0.65, \mathrm{df}=2, \mathrm{p}=0.72$; alleles: $\chi^{2}=0.001, \mathrm{df}=1, \mathrm{p}=0.98 .{ }^{*}$ Hardy-Weinberg equilibrium test for suicidal group: $\chi^{2}=0.50, \mathrm{df}=1, \mathrm{p}=0.48$, tHardy-Weinberg equilibrium test for control group: $\chi^{2}=0.20, \mathrm{df}=1, \mathrm{p}=0.66$. MDD: major depressive disorder 
HY Lee et al.

Table 3. Estimated distribution of haplotype frequencies for 5-HTTLPR and VNTR alleles in suicide subjects with MDD and control subjects

\begin{tabular}{lcccc}
\hline & \multicolumn{3}{c}{ Haplotypes* } \\
\cline { 2 - 5 } & L-10 (\%) & L-12 (\%) & S-10 (\%) & S-12(\%) \\
\hline Suicidal subjects with MDD & $12(4.5)$ & $25(9.5)$ & $42(15.9)$ & $185(70.1)$ \\
Control subjects & $8(3.3)$ & $12(4.9)$ & $44(18.0)$ & $180(73.8)$ \\
\hline
\end{tabular}

${ }^{*} \chi^{2}=4.70, \mathrm{df}=3, \mathrm{p}=0.20$. MDD: major depressive disorder, VNTR: various number of tandem repeats

Table 4. Clinical characteristics according to the serotonin transporter gene polymorphism (5-HTTVNTR) in suicidal subjects with major depressive disorder

\begin{tabular}{|c|c|c|c|c|c|c|c|c|c|}
\hline & \multicolumn{3}{|c|}{ 5-HTTVNTR genotype } & \multirow{2}{*}{$x^{2}$} & \multirow{2}{*}{$\mathrm{p}\left(\mathrm{p}_{\text {corr }}\right)$} & \multicolumn{2}{|c|}{ 5-HTTVNTR allele } & \multirow{2}{*}{$\mathrm{t}$} & \multirow{2}{*}{$\mathrm{p}\left(\mathrm{p}_{\text {corr }}\right)$} \\
\hline & $10 / 10$ & $10 / 12$ & $12 / 12$ & & & 10 & 12 & & \\
\hline Age(years) & $47.3 \pm 15.2$ & $34.0 \pm 12.6$ & $33.6 \pm 12.5$ & 3.19 & $0.20 *$ & & $34.3 \pm 12.9$ & 0.67 & 0.50 \\
\hline Gender (male/female) & $4 / 0$ & $15 / 18$ & $34 / 61$ & 7.1 & 0.03 & & & & \\
\hline HDRS & $15.0 \pm 7.2$ & $22.5 \pm 3.4$ & $23.7 \pm 2.9$ & 2.04 & $0.36^{*}$ & $18.4 \pm 8.21$ & $20.7 \pm 8.5$ & -1.23 & 0.22 \\
\hline LSARS-II & $4.2 \pm 1.6$ & $3.8 \pm 1.8$ & $4.1 \pm 2.2$ & 0.19 & $0.91^{*}$ & $3.8 \pm 1.8$ & $4.0 \pm 2.1$ & -4.81 & 0.63 \\
\hline RRR & $18.0 \pm 1.7$ & $30.7 \pm 13.5$ & $36.3 \pm 15.3$ & 7.93 & $0.02(0.04)^{*}$ & $28.7 \pm 13.2$ & $35.4 \pm 15.1$ & -2.54 & $0.01(0.02)$ \\
\hline
\end{tabular}

*Kruskal-Wallis test. HDRS: Hamilton's 17-item Depression Rating Scale, LSARS-II: the Lethality Suicide Attempt Rating Scale-updated, RRR: Risk-Rescue rating (RRR) system, $\mathrm{p}_{\text {corr: }}$ p-value after Bonferroni correction

Table 5. Clinical characteristics according to the serotonin transporter gene polymorphism (5-HTTLPR) in suicidal subjects with major depressive disorder

\begin{tabular}{|c|c|c|c|c|c|c|c|c|c|}
\hline & \multicolumn{3}{|c|}{ 5-HTTLPR genotype } & \multirow{2}{*}{$\chi^{2}$} & \multirow{2}{*}{$\mathrm{p}$} & \multicolumn{2}{|c|}{ 5-HTTLPR allele } & \multirow{2}{*}{$\mathrm{t}$} & \multirow{2}{*}{$\mathrm{p}$} \\
\hline & $10 / 10$ & $10 / 12$ & $12 / 12$ & & & $\mathrm{~L}$ & $S$ & & \\
\hline Age(years) & $30.5 \pm 7.0$ & $34.3 \pm 13.4$ & $35.0 \pm 13.1$ & 2.931 & $0.23^{*}$ & $33.4 \pm 12.2$ & $34.8 \pm 13.2$ & -1.05 & $0.29 *$ \\
\hline Gender (male/female) & $2 / 7$ & $18 / 27$ & $33 / 45$ & 1.35 & 0.51 & & & & \\
\hline HDRS & $19.6 \pm 9.2$ & $20.4 \pm 7.4$ & $20.7 \pm 9.2$ & 0.31 & $0.86^{*}$ & $19.6 \pm 7.7$ & $20.5 \pm 8.7$ & -5.05 & $0.62^{*}$ \\
\hline LSARS-II & $2.5 \pm 1.3$ & $4.3 \pm 2.1$ & $4.0 \pm 2.1$ & 4.43 & $0.11^{*}$ & $3.7 \pm 2.0$ & $4.1 \pm 2.1$ & -1.07 & $0.28^{*}$ \\
\hline RRR & $25.7 \pm 8.5$ & $34.8 \pm 14.6$ & $35.2 \pm 15.7$ & 3.13 & $0.21^{*}$ & $31.8 \pm 13.5$ & $35.1 \pm 15.4$ & -1.45 & $0.15^{*}$ \\
\hline
\end{tabular}

*Kruskal-Wallis test. HDRS: Hamilton's 17-item Depression Rating Scale, LSARS-II: the Lethality Suicide Attempt Rating Scale-updated, RRR: Risk-Rescue rating (RRR) system

II, RRR scores according to the 5-HTTLPR polymorphism (Table 5).

\section{DISCUSSION}

The aim of the present study was to identify the role of a serotonin transporter polymorphism on suicide behavior in major depressive disorder.

In this study, we found less number of the subjects with 10/ 10 than that of the subjects with other genotypes in control subjects and suicidal subjects, which is similar to rates found in other Asian populations. ${ }^{13}$ In this study, we demonstrated that the presence of the 10 allele was more frequent in suicidal subjects than in control subjects. In line with the present study, an earlier study found a significant association between suicide completion and the presence of at least one copy of the 5-HTTVNTR 10 allele. ${ }^{12}$ Further investigation regarding the frequencies of concurrence of tryptophan hydroxylase (TPH) and 5-HTTVNTR containing "lower activity" alleles (C/C and
$10 / 10$, respectively) revealed higher frequencies of lower activity in 5-HTT and TPH genotype combinations in suicidal victims than in control subjects. ${ }^{26}$ In a study performed in a Chinese population, however, no association was demonstrated between the 5-HTTVNTR polymorphism and suicidal history in mood disorder patients. ${ }^{27}$ It is difficult to conclude the association between the 5-HTTVNTR polymorphism and suicidal attempts was due to major depressive disorder, because that study was performed with participants with bipolar disorder or major depressive disorder who had an attempted suicide.

For 5-HTTLPR genotype, we could not find higher frequency of the genotype with lower activity in suicide subjects. A meta-analysis including many psychiatric disorders revealed significant association between 5-HTTLPR polymorphism and suicide..$^{28,29}$ In line with the present study including only major depressive disorder, however, there are many negative association studies between 5-HTTLPR and suicidal behavior in the patients with each specific psychiatric disorder. ${ }^{30,31}$ 
In the present study, no difference was noted in haplotype distribution between the suicidal subjects and control subjects. Similary, it was reported no statistically significant differences between serotonin transporter genotypes of controls and suicide victims. ${ }^{14}$ On the Contrary, It was reported a trend towards an increase of 5-HTTLPR allele L and 5-HTTVNTR allele 10 in Croatian suicide victims. ${ }^{6}$ Across all studies investigating links between haplotype and rate of suicide completion, however, there does appear to be a trend such that haplotypes that include 10 allele of 5-HTTVNTR are more frequently found in suicide victims. Regarding suicide attempts, it was found that the L10 haplotype in Russian females was associated with suicidal behavior, although the association was not significant after Bonferroni correction. ${ }^{11}$ With respect to patients of Asian ethnicity, neither the 5-HTTVNTR and 5-HTTLPR, nor the haplotype frequencies of these genes was shown to be significantly different between inpatients with suicidal attempt of different psychiatric disorders and controls in a Chinese population. ${ }^{13}$

Decreased levels of platelet 5-HTT have been observed in depressive patients. ${ }^{32}$ Furthermore, the impulsivity that often leads to suicide was significantly correlated with low 5-HTT in suicidal attempters. ${ }^{33}$ Because the 10-repeat allele displayed lower transcriptional activity than the 12 -repeat allele, ${ }^{8,34}$ it is possible that the 10-repeat allele could be a contributing factor for suicide. If so, this would support findings in the present study. Contrary to previous in vitro data, Bah and colleagues $^{35}$ assessed the availability of serotonin 5 -HTT in male suicide attempters with single photon emission computed tomography and found that the 12-repeat allele was related to low 5-HTT availability in whole brain. However, they reported that the abnormality in suicidal depression was localized to parts of the prefrontal cortex. ${ }^{36}$ Further studies with a larger number of subjects are needed in order to verify the 5-HTT contribution to activity in a specific brain region.

In the present study, LSARS-II scores did not differ with both serotonin transporter polymorphisms. In 5-HTTVNTR, however, RRR scores in the subjects with the 10/10 genotype or 10 carriers were lower than those in the subjects with other genotypes, indicating that there were fewer fatal attempts in 10/10 or 10 carriers. In contrast, other studies suggest the prevalence of 10 carriers was higher in completed suicides, therefore it is difficult to obtain a clear conclusion regarding the effect of 5-HTTVNTR on the lethality of suicide.

Some potential limitations of the present study should be noted. First, the distribution of 5-HTTVNTR in Korean is different from among Caucasians. The ratio of the 10/12 allele in control subjects in the present study was $0.09 / 0.91$, whereas the frequency of the 12 allele in general Caucasian population is $0.54-0.66 .{ }^{37}$ Furthermore, the 9 allele was absent in the
Korean population. The ratio of the $\mathrm{S} / \mathrm{L}$ allele among our subjects was approximately $0.76 / 0.24$, while the corresponding figure for Caucasians is $0.43 / 0.57$. As such, due to such ethnic differences in the distribution of the genotype, the results of this study are not necessarily applicable to other ethnicities. Second, the methods of suicide attempt were not controlled, although there is no statistical difference in the prevalence of fatality in suicidal attempts. Third, there was not a depressed group without a suicidal attempt to stand as an additional control group, and the total number of subjects was small. Fourth, controls were not clinically evaluated and the scale for stress or personality trait was not given to these subjects.

Notwithstanding of these limitations, this study is an important first step in examining the potential association between serotonin transporter gene polymorphisms and suicide behavior of major depressive disorder patients in a Korean population. Finally, identification of other polymorphisms which are related to 5-HTT activity or serotonin would be useful in identifying the role of the 5-HTT gene in the pathogenesis of suicidal behavior.

\section{Acknowledgments}

This study was supported by a grant of the Korean Health Technology R\&D Project, Ministry of Health \& Welfare, Republic of Korea (A120051).

\section{REFERENCES}

1. World Health Organization. The World Health Report 2001. Mental Health: New Understanding, New Hope. Geneva: WHO; 2001.

2. OECD. OECD Health Data 2008. Available: www.oecd.org. Accessed July $28,2008$.

3. Robins E, Murphy GE, Wilkinson RH Jr, Gassner S, Kayes J. Some clinical considerations in the prevention of suicide based on a study of 134 successful suicides. Am J Public Health Nations Health 1959;49:888899.

4. Leake A, Fairbairn AF, McKeith IG, Ferrier IN. Studies on the serotonin uptake binding site in major depressive disorder and control post-mortem brain: neurochemical and clinical correlates. Psychiatry Res 1991; 39:155-165.

5. Roy A. Genetic and biologic risk factors for suicide in depressive disorders. Psychiatr Q 1993;64:345-358.

6. Hranilovic D, Stefulj J, Schwab S, Borrmann-Hassenbach M, Albus M, Jernej B, et al. Serotonin transporter promoter and intron 2 polymorphisms: relationship between allelic variants and gene expression. Biol Psychiatry 2004;55:1090-1094.

7. Lesch KP, Balling U, Gross J, Strauss K, Wolozin BL, Murphy DL, et al. Organization of the human serotonin transporter gene. J Neural Transm Gen Sect 1994;95:157-162.

8. MacKenzie A, Quinn J. A serotonin transporter gene intron 2 polymorphic region, correlated with affective disorders, has allele-dependent differential enhancer-like properties in the mouse embryo. Proc Natl Acad Sci U S A 1999;96:15251-15255.

9. Ogilvie AD, Battersby S, Bubb VJ, Fink G, Harmar AJ, Goodwim GM, et al. Polymorphism in serotonin transporter gene associated with susceptibility to major depression. Lancet 1996;347:731-733.

10. Liu W, Gu N, Feng G, Li S, Bai S, Zhang J, et al. Tentative association of the serotonin transporter with schizophrenia and unipolar depression but not with bipolar disorder in Han Chinese. Pharmacogenetics 1999; 9:491-495. 
11. Gaysina D, Zainullina A, Gabdulhakov R, Khusnutdinova E. The serotonin transporter gene: polymorphism and haplotype analysis in Russian suicide attempters. Neuropsychobiology 2006;54:70-74.

12. Lopez de Lara C, Dumais A, Rouleau G, Lesage A, Dumont M, Chawky $\mathrm{N}$, et al. STin 2 variant and family history of suicide as significant predictors of suicide completion in major depression. Biol Psychiatry 2006;59: 114-120.

13. Shen Y, Li H, Gu N, Tan Z, Tang J, Fan J, et al. Relationship between suicidal behavior of psychotic inpatients and serotonin transporter gene in Han Chinese. Neurosci Lett 2004;372:94-98.

14. Pungercic G, Videtic A, Pestotnik A, Pajnic IZ, Zupanc T, Balazic J, et al. Serotonin transporter gene promoter (5-HTTLPR) and intron 2 (VNTR) polymorphisms: a study on Slovenian population of suicide victims. Psychiatr Genet 2006;16:187-191.

15. Greenberg BD, Tolliver TJ, Huang SJ, Li Q, Bengel D, Murphy DL. Genetic variation in the serotonin transporter promoter region affects serotonin uptake in human blood platelets. Am J Med Genet 1999;88:83-87.

16. Lesch KP, Bengel D, Heils A, Sabol SZ, Greenberg BD, Petri S, et al. Association of anxiety-related traits with a polymorphism in the serotonin transporter gene regulatory region. Science 1996;274:1527-1531.

17. Collier DA, Stober G, Li T, Heils A, Catalano M, Di Bella D, et al. A novel functional polymorphism within the promoter of the serotonin transporter gene: possible role in susceptibility to affective disorders. Mol Psychiatry 1996;1:453-460.

18. Malhotra AK, Goldman D, Mazzanti C, Clifton A, Breier A, Pickar D. A functional serotonin transporter (5-HTT) polymorphism is associated with psychosis in neuroleptic-free schizophrenics. Mol Psychiatry 1998;3:328-332.

19. Stober G, Jatzke S, Heils A, Jungkunz G, Fuchs E, Knapp M, et al. Susceptibility for schizophrenia is not influenced by a functional insertion/ deletion variant in the promoter of the serotonin transporter gene. Eur Arch Psychiatry Clin Neurosci 1998;248:82-86.

20. Bonnet-Brilhault F, Laurent C, Thibaut F, Campion D, Chavand O, Samolyk D, et al. Serotonin transporter gene polymorphism and schizophrenia: an association study. Biol Psychiatry 1997;42:634-636.

21. Hamilton M. A rating scale for depression. J Neurol Neurosurg Psychiatry 1960;23:56-62.

22. Weisman AD, Worden JW. Risk-rescue rating in suicide assessment. Arch Gen Psychiatry 1972;26:553-560.

23. Smith K, Conroy RW, Ehler BD. Lethality of suicide attempt rating scale. Suicide Life Threat Behav 1984;14:215-242.

24. Berman AL, Shepherd G, Silverman MM. The LSARS-II: Lethality of Suicide Attempt Rating Scale-Updated. Suicide Life Threat Behav 2003;
33:261-276.

25. Kim YK, Paik JW, Lee SW, Yoon D, Han C, Lee BH. Increased plasma nitric oxide level associated with suicide attempt in depressive patients. Prog Neuropsychopharmacol Biol Psychiatry 2006;30:1091-1096.

26. Jernej B, Stefulj J, Hranilovic D, Balija M, Skavic J, Kubat M. Intronic polymorphism of tryptophan hydroxylase and serotonin transporter: indication for combined effect in predisposition to suicide. J Neural Transm 2004;111:733-738.

27. Yen FC, Hong CJ, Hou SJ, Wang JK, Tsai SJ. Association study of serotonin transporter gene VNTR polymorphism and mood disorders, onset age and suicide attempts in a Chinese sample. Neuropsychobiology 2003;48:5-9.

28. Li D, He L. Meta-analysis supports association between serotonin transporter (5-HTT) and suicidal behavior. Mol Psychiatry 2007;12:47-54.

29. Antypa N, Serretti A, Rujescu D. Serotonergic genes and suicide: a systematic review. Eur Neuropsychopharmacol 2013;23:1125-1142.

30. De Luca V, Tharmalingam S, King N, Strauss J, Bulgin N, Kennedy JL. Association study of a novel functional polymorphism of the serotonin transporter gene in bipolar disorder and suicidal behaviour. Psychopharmacology (Berl) 2005;182:128-131.

31. De Luca V, Zai G, Tharmalingam S, de Bartolomeis A, Wong G, Kennedy JL. Association study between the novel functional polymorphism of the serotonin transporter gene and suicidal behaviour in schizophrenia. Eur Neuropsychopharmacol 2006;16:268-271.

32. Ellis PM, Salmond C. Is platelet imipramine binding reduced in depression? A meta-analysis. Biol Psychiatry 1994;36:292-299.

33. Lindstrom MB, Ryding E, Bosson P, Ahnlide JA, Rosen I, TraskmanBendz L. Impulsivity related to brain serotonin transporter binding capacity in suicide attempters. Eur Neuropsychopharmacol 2004;14:295300.

34. Fiskerstrand CE, Lovejoy EA, Quinn JP. An intronic polymorphic domain often associated with susceptibility to affective disorders has allele dependent differential enhancer activity in embryonic stem cells. FEBS Lett 1999;458:171-174.

35. Bah J, Lindstrom M, Westberg L, Manneras L, Ryding E, Henningsson $S$, et al. Serotonin transporter gene polymorphisms: Effect on serotonin transporter availability in the brain of suicide attempters. Psychiatry Res 2008;162:221-229.

36. Mann JJ. Neurobiology of suicidal behaviour. Nat Rev Neurosci 2003;4: 819-828.

37. Fan JB, Sklar P. Meta-analysis reveals association between serotonin transporter gene STin2 VNTR polymorphism and schizophrenia. Mol Psychiatry 2005;10:928-938, 891. 